\title{
O IMPACTO DO PROBLEMA AMBIENTAL DO FLUIDO DE CORTE NAS INDÚSTRIAS E NOVAS ALTERNATIVAS PARA SUA UTILIZAÇÃO MAIS RACIONAL NOS PROCESSOS DE RETIFICAÇÃO
}

\author{
Eduardo Carlos Bianchi ${ }^{1}$ \\ Paulo Roberto Aguiar ${ }^{2}$
}

Rodrigo Santana Destro ${ }^{3}$

Marcos Hiroshi Oikawa ${ }^{4}$

RESUMO: Devido à constante preocupação do meio ambiente, o uso de fluidos de corte tem se tornado um problema para a indústria mecânica atual por se tratar de substâncias tóxicas. Seu uso e sua dificuldade de descarte devido rígida Legislação Ambiental, faz com que o fluido de corte seja responsável por uma grande parte do custo final do processo, provocando, desse modo, um grande interesse em pesquisas referentes a métodos alternativos de forma e quantidade de fluido de corte utilizado. Ao lado das vantagens tecnológicas associadas com o uso dos fluidos de corte estão os enormes perigos atrelados a estes, e que são nocivos ao meio ambiente e à saúde das pessoas. A contaminação do solo, água e ar podem decorrer de vazamentos e perdas, emissões, água de lavagem e da própria disposição dos fluidos de corte.Os componentes dos fluidos de corte como bactericidas e fungicidas reagem com outros produtos inseridos no processo de corte, tornando os fluidos, materiais que podem vir a causar doenças. Assim, este trabalho tem

\footnotetext{
${ }^{1}$ Engenheiro Mecânico, UNESP, Professor Titular. bianchi@feb.unesp.br

${ }^{2}$ Engenheiro Eletricista, UNESP, Professor Adjunto. aguiarpr@feb.unesp.br

${ }^{3}$ Aluno de Engenharia Mecânica, UNESP, Bolsista FAPESP.rod_destro@hotmail.com

${ }^{4}$ Aluno de Engenharia Mecânica, UNESP, Bolsista FAPESP. marcos_oiakawa@yahoo.com.br
} 
como objetivo apresentar a utilização do fluido de corte por mínima quantidade de lubrificação como alternativa para se minimizar o impacto ambiental das indústrias mecânicas.

Palavras-chave: Preocupação ambiental. Uso do fluido de corte. Retificação.

\section{INTRODUÇÃO}

O uso do fluido de corte nas indústrias acaba se tornando um problema devido à sua manutenção e descarte pelo fator da contaminação ambiental. Segundo Sokovic \& Mijanovic (2001), os fluidos de corte podem ser eliminados dentro da própria empresa ou por companhias de eliminação de fluido e, dependendo da qualidade e do modo de eliminação, pode - se resultar em algum tipo de poluição de terra, de ar, ou de água.

Segundo Ebbrell et al. (2000) e Nguyen \& Zhang (2003) as principais funções do fluido de corte são: lubrificação, refrigeração do conjunto peça/ferramenta, e retirada do cavaco da zona de corte. A lubrificação pelo fluido de corte reduz as forças envolvidas no processo evitando assim a geração de calor na zona de corte.

Segundo Oliveira et. al (1998) o processo de retificação tem como objetivo produzir componentes de precisão com excelente qualidade dimensional, de forma e com elevado acabamento superficial. É usualmente empregado nas etapas finais de produção e por este motivo tornou-se um processo de responsabilidade, no qual não se admite perdas das peças, pois nessa fase estas já possuem um elevado valor agregado, devido às inúmeras operações a que foram submetidas previamente.

Segundo Irani et al. (2005), um dos maiores fatores limitantes no processo de retificação é o dano térmico. Este dano pode ser reduzido pela aplicação do fluido de corte que remove o calor criado pela interação da ferramenta através da transferência de calor. Há também uma diminuição de geração de calor decorrente da diminuição do atrito entre a peça e ferramenta, dada pela ação lubrificante do fluido de corte.

A não utilização desses fluidos poderá ocasionar a queda de rendimento do rebolo devido ao aumento da temperatura no processo, além da perda da qualidade dimensional e acabamento superficial das peças retificadas, que podem ser provocados pelo entupimento dos poros do rebolo. Uma das alternativas seria a usinagem na ausência do fluido, a seco. As vantagens desse processo são visíveis: menor impacto 
ambiental, menor risco de saúde pela parte dos trabalhadores, e economia na compra, manutenção e descarte do próprio fluido. Entretanto estas vantagens são contrapostas pelos problemas provenientes da ausência das funções primarias que o próprio fluido de corte proporciona. Além disso, casos de retificação a seco são muito raros na literatura.

Desse modo, há uma constante pesquisa na procura de técnicas alternativas, economicamente viáveis e tecnicamente adequadas, de utilização desses fluidos refrigerantes.

Segundo Smith (1996), ao lado das vantagens tecnológicas associadas com o uso dos fluidos de corte estão os enormes perigos atrelados a estes, e que são nocivos ao meio ambiente e à saúde das pessoas. A contaminação do solo, água e ar podem decorrer de vazamentos e perdas, emissões, água de lavagem e da própria disposição dos fluidos de corte. Os componentes dos fluidos de corte como bactericidas e fungicidas reagem com outros produtos inseridos no processo de corte, tornando os fluidos, materiais que podem vir a causar doenças.

Klocke et. al (2000) reporta que a contaminação do solo, água e ar é decorrente, principalmente, de vazamentos, perdas, emissões, água da lavagem de reservatórios e da própria disposição dos fluidos de corte.

Segundo Sokovic \& Mijanovic (2001), dependendo da qualidade e do modo de eliminação, pode-se resultar em algum tipo de poluição de terra, de ar, ou de água.

Segundo Silliman (1992), melhor que descartar o fluido é reciclar o mesmo. O fluido de corte usado é removido da máquina e os resíduos são separados pelo processo de reciclagem. O fluido limpo é então adicionado ao reciclado e a nova mistura volta para dentro da máquina. $O$ processo de reciclagem elimina a freqüência com que o fluido de corte é descartado. Isto pode trazer um grande benefício financeiro, pois os custos com os descartes são elevados.

A fim de satisfazer as leis governamentais e locais sobre a poluição da água, todo fluido de corte solúve em água deveria sofrer uma espécie de tratamento antes de ser disposto no rio, córrego ou sistema municipal de esgoto. Os produtos químicos considerados como poluentes da água são óleo, nitritos, fenóis, fosfatos e metais pesados. O conteúdo do óleo pode ser quebrado/separado da emulsão por um tratamento de ácido ou sulfato de alumínio. Segundo Baradie (1996), em alguns estados dos EUA, 
efluentes contendo mais que 2 partes por bilhão de fenol ou derivados fenólicos são proibidos.

O objetivo deste trabalho é apresentar a utilização do fluido de corte por mínima quantidade de lubrificação como alternativa para se minimizar o impacto ambiental das indústrias mecânicas

\section{MATERIAL E MÉTODO}

O banco de ensaios é composto por uma retificadora tangencial plana da marca SULMECÂNICA, modelo 1055E; um rebolo vitrificado superabrasivo de CBN da empresa Nikkon Ferramentas de Corte Ltda, cujas dimensões são: diâmetro externo de $350 \mathrm{~mm}$, diâmetro interno de $127 \mathrm{~mm}$, largura de $20 \mathrm{~mm}$, com $5 \mathrm{~mm}$ de espessura de material abrasivo; corpos-de-prova de aço ABNT 4340, temperado e revenido (dureza média de 54 $\mathrm{HRc})$.

A força tangencial de corte foi medida pela determinação da potência elétrica consumida pelo motor de acionamento do eixo árvore do rebolo, com o monitoramento dos valores de tensão e corrente elétrica, provenientes deste motor elétrico.

Para tal, um módulo eletrônico é utilizado para transformação dos valores de corrente elétrica e tensão (provenientes do motor) em sinais de tensões compatíveis para serem enviados a uma placa de aquisição de dados e manipulados pelo programa de aquisição de dados, que foi desenvolvido, utilizando-se o software LabView 7.1®, da National Instruments ${ }^{\circledR}$.

O sinal de emissão acústica (EA) foi monitorado em tempo real, pelo seu valor médio quadrático ( $r m s$ ou Root Mean Square), utilizando um aparelho da marca Sensis, modelo DM42. O sensor acústico foi acoplado à morça em que a peça a ser retificada estava apoiada, sendo esta morça fixa na mesa magnética da máquina retificadora. Este sensor detecta as variações nas emissões acústicas, enviadas para o módulo de EA, o qual as transforma em tensões elétricas.

O fluido de corte utilizado no método convencional foi um óleo solúvel semisintético, ULTRACUT 370, da empresa ROCOL. Este fluido foi diluído na proporção de 
1:20, isto é, fez-se a diluição de uma parte deste fluido em 20 partes de água, o que equivale a uma concentração de $5 \%$ de fluido na emulsão, conforme indicado pelo fabricante. No método convencional, esse fluido é aplicado abundantemente na interface de contato peça/ferramenta.

O sistema de MQL é composto basicamente por: compressor, regulador de pressão, medidor de vazão de ar, dosador e bocal. O equipamento de mínima quantidade de lubrificação permite uma fina regulagem do volume de lubrificante/ar separadamente, por meio de um registro tipo agulha. Nesta pesquisa, utilizou-se o aparelho da Accu-Lube, modelo 79053D. O fluido de corte utilizado foi o Accu-Lube LB 1000 do fabricante ITW Chemical Products Ltda, que é um óleo vegetal biodegradável com aditivos de extrema pressão, para operações severas, e antioxidantes.

Preparado o banco de ensaios, realizaram-se ensaios preliminares, com o objetivo de se definir os parâmetros de usinagem. Mantendo-se a velocidade da peça, e a velocidade periférica do rebolo constantes, variou-se a profundidade de corte, o que acarretou em diferentes espessuras de corte equivalente. A Tabela 1 mostra os parâmetros de usinagem adotados.

TABELA 1 - Parâmetros de usinagem adotados.

\begin{tabular}{|c|c|c|c|}
\hline $\begin{array}{c}h_{e q} \text { (espessura } \\
\text { equivalente de corte) }\end{array}$ & $\begin{array}{c}a \text { (profundidade de } \\
\text { corte) }\end{array}$ & $\begin{array}{c}V_{w} \text { (velocidade da } \\
\text { peça) }\end{array}$ & $\begin{array}{c}V_{s} \text { (velocidade } \\
\text { periférica do rebolo) }\end{array}$ \\
\hline $0,02 \mathrm{~mm}$ & $20 \mu \mathrm{m}$ & $0,033 \mathrm{~m} / \mathrm{s}$ & $32 \mathrm{~m} / \mathrm{s}$ \\
\hline $0,05 \mathrm{~mm}$ & $50 \mu \mathrm{m}$ & $0,033 \mathrm{~m} / \mathrm{s}$ & $32 \mathrm{~m} / \mathrm{s}$ \\
\hline $0,08 \mathrm{~mm}$ & $80 \mu \mathrm{m}$ & $0,033 \mathrm{~m} / \mathrm{s}$ & $32 \mathrm{~m} / \mathrm{s}$ \\
\hline
\end{tabular}

O critério de parada foi o volume específico de material removido, adotado em $5000 \mathrm{~mm}^{3} / \mathrm{mm}$. Como há três diferentes espessuras de corte equivalente, o intervalo para se obter o volume específico estipulado é diferente para cada situação.

A medição de rugosidade foi feita medindo-se o parâmetro $R_{a}$, com um rugosímetro da marca Taylor Hobson, modelo Surtronic 3+, a cada $1000 \mathrm{~mm}^{3} / \mathrm{mm}$ de material removido. Para cada espessura equivalente de corte foram testados dois métodos diferentes de lubri-refrigeração, o convencional e a técnica de mínima quantidade de lubrificante (MQL). Para cada método, a repetibilidade foi de três experimentações. Assim, foram realizados 18 ensaios no total. 
Ao final do ensaio, efetuava-se a medição do desgaste do rebolo. Esse procedimento foi feito utilizando um corpo-de-prova de aço ABNT 1045. O desgaste impresso nos corpos foi medido em uma máquina de coordenadas da empresa TESA, modelo Micro-Hite 3D Direct Computer Control (DCC).

\section{RESULTADOS E DISCUSSÃO}

Os dados obtidos sofreram tratamentos estatísticos, buscando a melhor maneira de análise. Como as variáveis velocidade do rebolo e velocidade da peça são constantes, alterando-se a profundidade de corte, altera-se a espessura equivalente de corte.

Com os dados obtidos do banco de aquisição gerou-se a Figura 1, na qual se observa a força tangencial de corte ao longo do ensaio. Pode-se observar nesta figura que para o MQL nas condições de espessura equivalente de corte de 0,02 e 0,05 mm a força de corte é menor que aquela gerada no método convencional. Isso se explica pelo fato de O MQL nestas condições ser capaz de lubrificar a região de corte de forma mais efetiva, vencendo a barreira de ar gerada pelo rebolo em seu movimento. Sendo assim, diminui-se a parcela de esforço gasto entre atrito da peça com a ferramenta.

Já para uma espessura equivalente de corte de $0,08 \mathrm{~mm}$, a força observada para o MQL é maior que a para o método convencional. Em ambos os métodos, essa condição de usinagem é mais rude, o que se confirma pela elevação da força de corte. $O$ fato de as forças no MQL serem maiores refere-se à dificuldade de lubrificação eficiente do processo nesta condição mais severa de corte, o que gera grandes esforços no processo de corte. Além da lubrificação ineficiente, a refrigeração da zona de corte pelo fluxo de ar é incapaz de minimizar a geração de calor excessivo. 

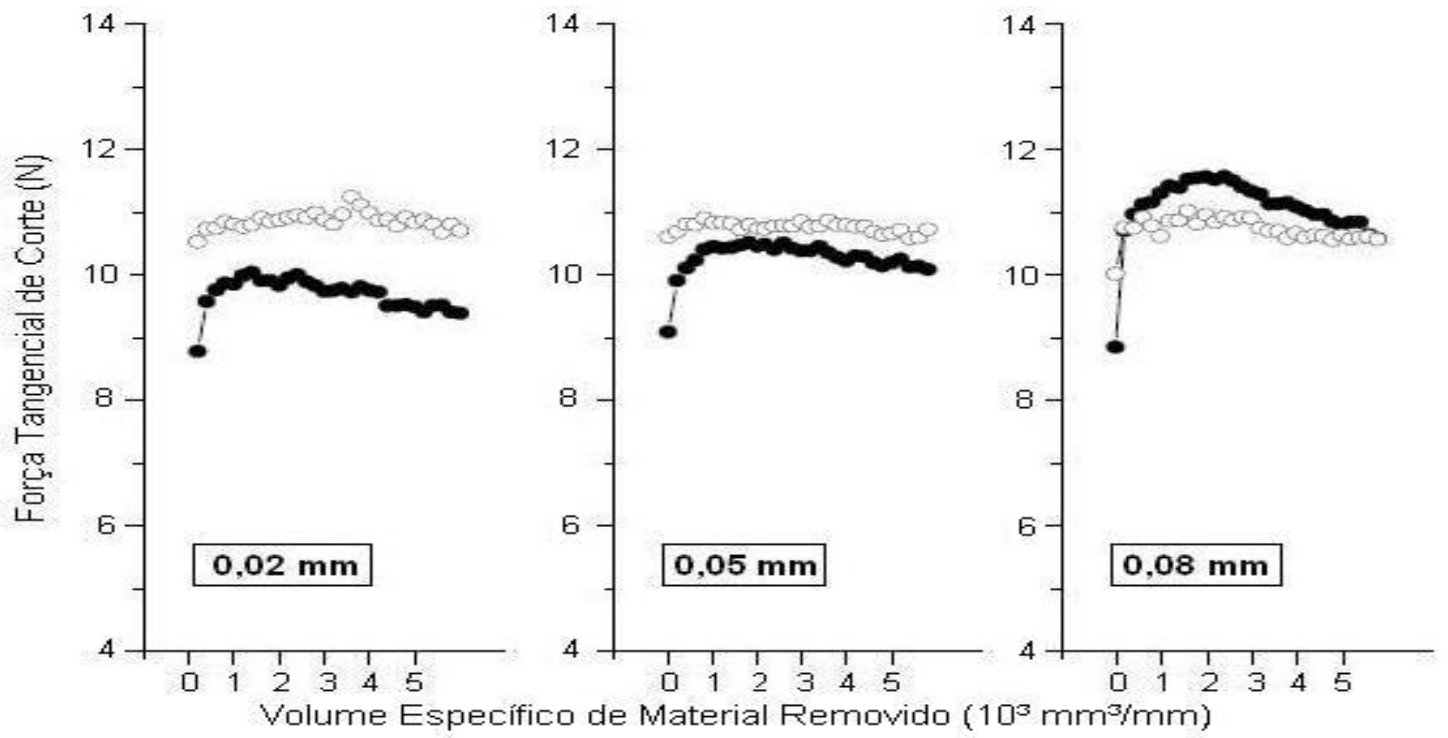

FIGURA 1 - Dados de força tangencial de corte.

Pode-se concluir que com o aumento da profundidade de corte, o que no caso desta pesquisa acarreta um aumento na espessura equivalente de corte, tem-se a tendência de aumentar os valores médios da força tangencial de corte. Trata-se de uma suposição coerente, pois o aumento da profundidade de corte faz com que haja maior área de contato entre o rebolo e a peça, e embora o número de grãos em contato também seja maior, o esforço para se remover um maior volume de material é crescente, o que tem como consequência as maiores forças de corte.

A importância da análise da variável rugosidade deve-se ao fato de que o acabamento superficial afeta de forma significativa a resistência à fadiga das peças quando estas são submetidas a esforços. A rugosidade de uma peça ainda está diretamente ligada à lubrificação e depende principalmente do tamanho do grão abrasivo presente no rebolo, das condições de dressagem, e da taxa de remoção de material.

Assim, devido à importância da rugosidade nas peças retificadas, realizou-se neste trabalho a medição desta variável, sendo adotado o parâmetro rugosidade média $\left(R_{a}\right)$. Na Figura 2, os valores de rugosidade são dados em micrometros, sendo que foram obtidos a partir da média aritmética de todos os ensaios de mesma espessura equivalente de corte, ou seja, a média de quinze valores de medição, cinco em cada repetição de ensaio. 


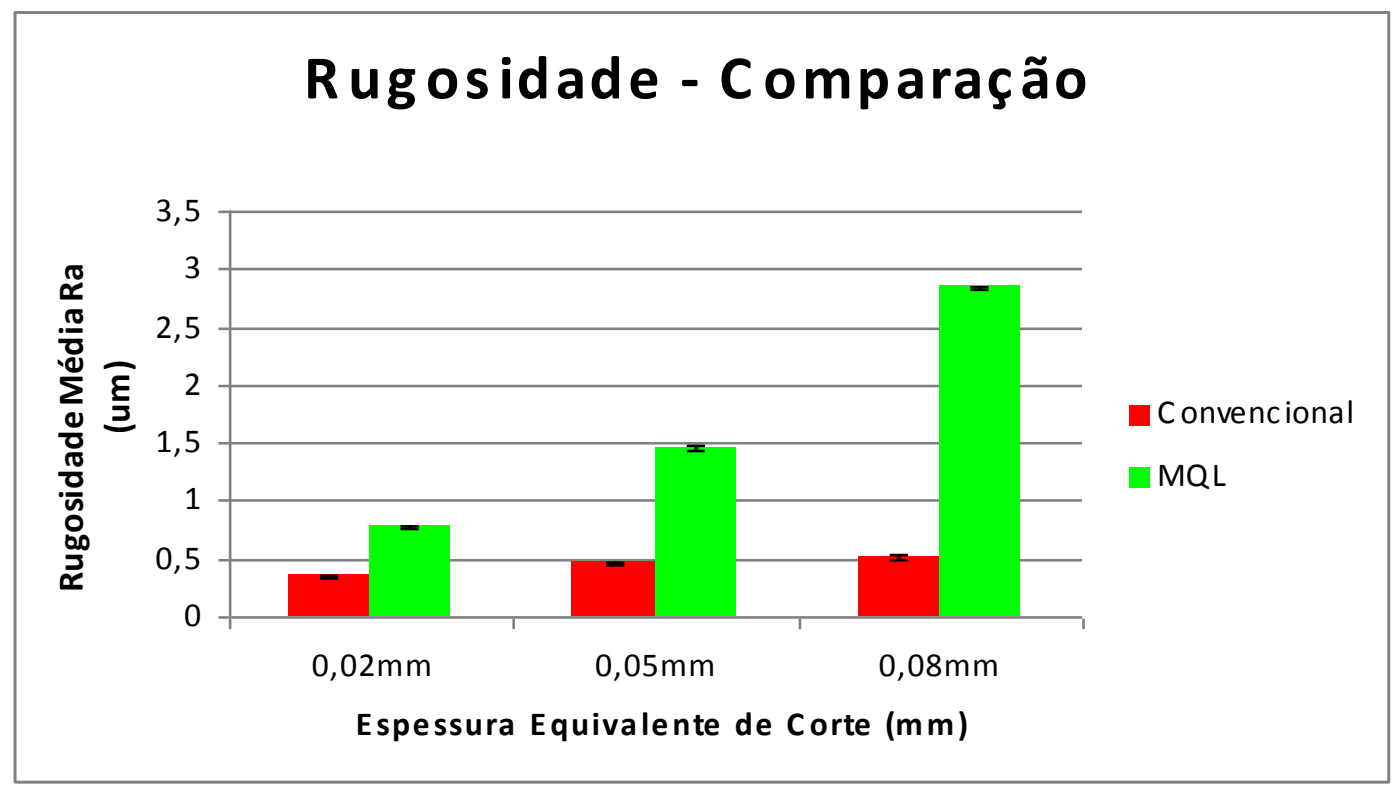

FIGURA 2 - Comparação da rugosidade entre os métodos testados.

Verifica-se que todos os valores de rugosidade obtidos na lubri-refrigeração convencional ficaram abaixo dos valores obtidos no método de MQL. No caso de 0,08 $\mathrm{mm}$ de espessura equivalente de corte, os valores de rugosidade do MQL chegam a ser quase seis vezes maiores que os valores convencionais.

A faixa de valores de rugosidade média aceitável para o processo de retificação está entre 0,2 e 1,6 $\mu \mathrm{m}$. Assim, todos os valores obtidos no método convencional estão dentro da faixa de tolerância, apresentando até valores bem satisfatórios. Para o MQL, no entanto, os valores de rugosidade obtidos com $0,08 \mathrm{~mm}$ de espessura equivalente de corte estão fora da faixa de tolerância considerada, o que desclassifica o processo quanto à sua qualidade superficial. No caso da espessura de corte $0,05 \mathrm{~mm}$, os valores estão próximos ao limite, mas ainda podem ser considerados válidos. Na melhor condição, 0,02 $\mathrm{mm}$ de espessura de corte, os valores apresentados pelo MQL são maiores que os apresentados pelo método convencional, no entanto o MQL apresenta-se como uma opção considerável, mesmo para acabamento.

As causas dessas variações podem ser explicadas pelo fato de que o método convencional, com seu fluxo abundante de fluido, é capaz de retirar os cavacos da zona de corte, e melhorar a lubrificação da região, diminuindo o coeficiente de atrito entre ferramenta e peça. O fato de o MQL ser ineficiente nestas tarefas, como comprovado com o aumento da espessura equivalente de corte, faz com que o cavaco permaneça na zona 
de corte, prejudicando a remoção de material. No caso do MQL, quanto maior o cavaco gerado, maior a dificuldade em removê-lo, maiores problemas na qualidade superficial, o que é novamente comprovado com os altos valores de rugosidade. O fluxo de ar é eficiente na remoção do cavaco gerado no corte a $0,02 \mathrm{~mm}$ de espessura. No entanto sua eficiência diminui com o aumento desta espessura de corte.

O desgaste do rebolo se deve a três fatores principais: desgaste do aglomerante, desgaste do grão abrasivo, e friabilidade dos grãos. Trata-se de uma variável de extrema importância no processo de retificação, já que quanto maior o desgaste do rebolo, menor a vida útil deste. A Figura 3 apresenta o desgaste diametral do rebolo para cada espessura equivalente de corte para os dois tipos de lubri-refrigeração considerados.

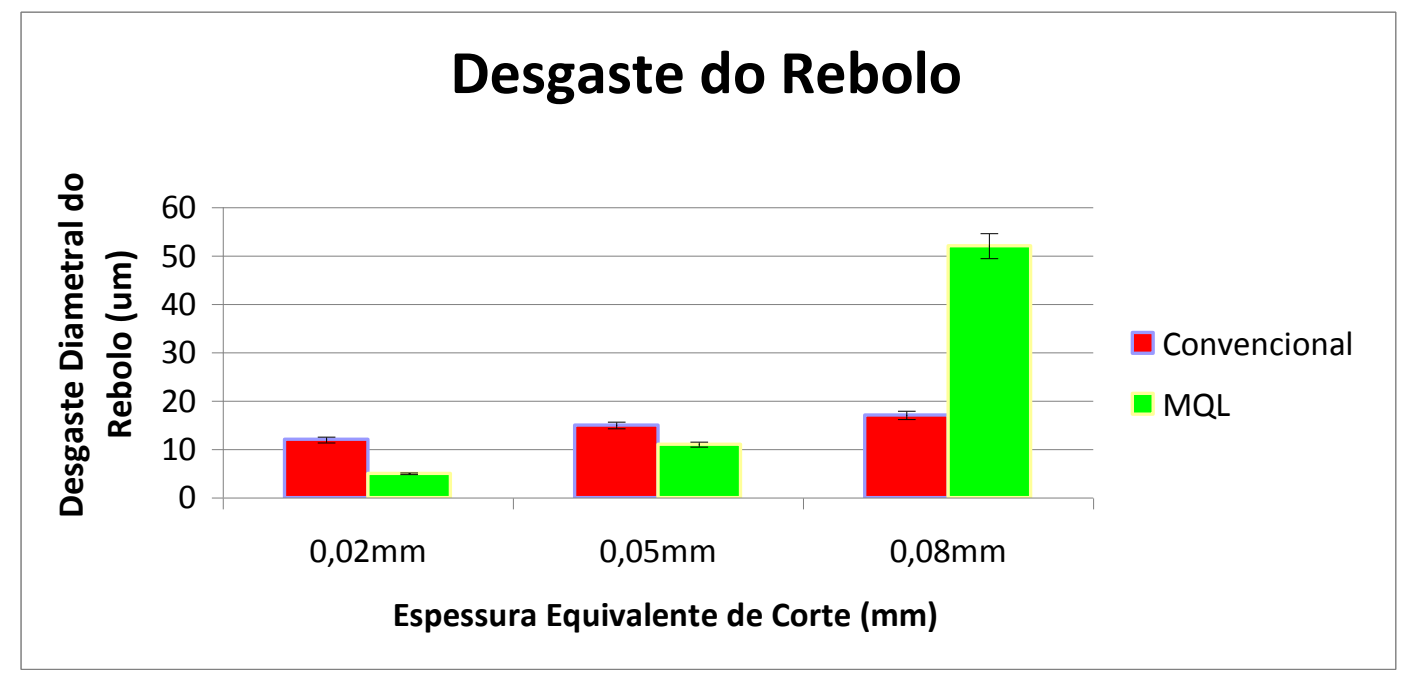

FIGURA 3 - Comparação do desgaste do rebolo.

Pode-se notar que o desgaste diametral do rebolo na técnica de MQL foi menor nas espessuras equivalentes de corte de 0,02 e $0,05 \mathrm{~mm}$, enquanto que para a espessura de $0,08 \mathrm{~mm}$, o valor obtido no MQL foi muito maior que o obtido no método convencional. Esses comportamentos observados são também vistos nos dados de força de corte e energia específica, uma vez que quanto maior a solicitação a que o rebolo é submetido, maiores forças de corte são necessárias, mais energia se gasta, e consequentemente, maior o desgaste da ferramenta.

É indiscutível que quanto maior a penetração do fluido lubri-refrigerante na zona de corte, menor o desgaste por atrito entre a ferramenta e o cavaco, e melhor a remoção 
do calor gerado. Deve-se levar em consideração também a porosidade do rebolo, pois esta é responsável pelo alojamento do cavaco gerado, possibilitando assim melhor acesso do fluido à zona de corte, com conseqüente melhora na lubrificação, diminuindo o desgaste por atrito.

O rebolo utilizado é um rebolo de $\mathrm{CBN}$ com ligante vitrificado. Este tipo de ligante é menos suscetível ao desgaste erosivo da ação do cavaco arrancado sobre o ligante, proporcionando uma maior força de retenção do ligante sobre o grão abrasivo e, conseqüentemente, diminuindo a perda diametral do rebolo. Esse é um dos motivos pelo qual o ligante vitrificado tem tido grande aceitação na produção industrial (KOPAC \& KRAJNIK, 2006).

Sendo assim, no MQL a baixas profundidades de corte, partes do cavaco misturado ao óleo pulverizado alojam-se nos poros do rebolo, permitindo que uma porção do lubrificante atinja melhor a zona de corte, diminuindo o desgaste por atrito, permitindo também que o fluxo de ar remova parte do calor gerado, melhorando a refrigeração do local. Assim, mesmo que esta condição de alojamento gere na superfície usinada maior rugosidade, ela é responsável por contribuir com a diminuição do desgaste da ferramenta.

No entanto, quando o cavaco gerado fica maior, como quando se aumenta a espessura equivalente de corte, os poros não são capazes de alojar esse cavaco maior, e o fluxo de ar é ineficiente em removê-lo da zona de corte. Assim, o cavaco atrapalha o corte e aumenta os esforços abrasivos da ferramenta sobre a peça, diminuindo a capacidade de lubrificação da zona de corte, danificando a superfície, e acarretando maior desgaste diametral do rebolo.

\section{CONCLUSÕES}

A partir dos dados obtidos experimentalmente utilizando dois diferentes métodos de lubri-refrigeração, o convencional e o de mínima quantidade de lubrificação (MQL), pode-se concluir para a retificação plana de aço ABNT 4340 temperado e revenido, que o método de mínima quantidade de lubrificante é uma alternativa viável quando utilizado para pequenas profundidades de corte. Esse método é uma alternativa considerável, pois 
embora apresente um acabamento superficial pior que o método convencional, a vida útil da ferramenta de corte é melhor, o que garante ao método bom custo-benefício.

Assim, mostra-se que o MQL pode ser utilizado nas indústrias diminuindo o uso de fluidos de corte, consequentemente reduzindo o impacto ambiental de seu descarte, e visando a melhoria na qualidade de trabalho dos operadores.

\section{REFERÊNCIAS}

ATTANASIO A., GELFI M., GIARDINI C., REMINO C., Minimal quantity lubrication in turning: Effect on tool wear, Wear 260 (2006) 333-338.

BLENKOWSKI K., Coolants and lubricants: part 1-the truth, Manufacturing Engineering March (1993) 90-96.

CAMPBELL, J. D. Optimized Coolant Application. In: 1st International Machining and Grinding Conference, Technical Paper, MR95-211, Society of Manufacturing Engineers, 12-14 September, Deabornn, Michigan, 1995, p. 895-904.

EBBRELL S., WOOLLEY N.H., TRIDIMAS Y.D., ALLANSON D.R., ROWE W.B., Effects of cutting fluid application methods on the grinding process, International Journal of Machine Tools and Manufacture 40 (2) (2000) 209-223.

EL BARADIE, M. A. Cutting fluids: Part I. Characterisation. Journal of Materials Processing Technology, Irlanda, Vol. 56, p. 786-797, 1996.

IRANI R.A., BAUER R.J., WARKENTIN A., A review of cutting fluid application in the grinding process, International Journal of Machine Tools \& Manufacture 45 (2005) 16961705.

KLOCKE, F.; BECK, T.; EISENBLÄTTER, G.; FRITSCH, R.; LUNG, D.; PÖHLS, M. "Applications of minimal quantity lubrification (MQL) in cutting and grinding", Institute of Machine Tools and Production Engineering, University of Technology, 2001 
KLOCKE, F.; EISENBLÄTTER, G. "Dry cutting”, Annals of the CIRP, v. 46, n.2, p. 519526, 1997.

NGUYEN T., ZHANG L.C., An assessment of the applicability of cold air and oil mist in surface grinding, Journal of Materials Processing Technology 140 (1-3) (2003) 224-230.

NOVASKI, O.; DÖR, J. "Usinagem Quase a Seco" Revista Máquinas e Metais, Ano XXXVI, No 406, P 34-41, Novembro 1999.

OBIKAWA T., KAMATA Y., SHINOZUKA, J. High-speed grooving with applying MQL, International Journal of Machine Tools \& Manufacture 46 (2006) 1854-1861

OLIVEIRA, J. F. G. (1998). Tópicos avançados sobre o processo de retificação, Reimpressão em setembro de 1998.

ROWE W. B.; CHEN Y.; MORUZZI J. L.; MILLS B. A generic intelligent control system for grinding. Computer Integrated Manufacturing Systems. Vol 10, nº 3, p. 231-241, 1997.

SILLIMAN, J. D. (Ed.). Cutting and grinding fluids: selection and application. Dearborn Michigan, SME, Second Edition, 1992, p. 119-135, ISBN: 0-87263-423-X.

SOKOVIC M., MIJANOVIC K., Ecological aspects of the cutting fluids and its influence on quantifiable parameters of the cutting processes, Journal of Materials Processing Technology 109 (2001) 181-189.

WEBSTER, J. A. Selection of coolant type and application technique in grinding. Supergrind, University of Connecticut, USA, 1995, p. 205-220.

YOUNG P.; BYRNE G.; COTTERE M.; Manufacturing and the Environment, International Jounal of Advanced Manufacturing Technology International Jounal of Advanced Manufacturing Technology, (1997) 13:488-493.

ZIELASKO W., "Dry cutting in large scale production", VDI Report 1240, VDI Verlag, pp. 93-110, 1996. 